\title{
BMJ Open Factors associated with polypharmacy in primary care: a cross-sectional analysis of data from The English Longitudinal Study of Ageing (ELSA)
}

\author{
Natasha Slater, Simon White, Rebecca Venables, Martin Frisher
}

To cite: Slater $\mathrm{N}$, White $\mathrm{S}$, Venables $\mathrm{R}$, et al. Factors associated with polypharmacy in primary care: a crosssectional analysis of data from The English Longitudinal Study of Ageing (ELSA). BMJ Open 2018;8:e020270. doi:10.1136/ bmjopen-2017-020270

- Prepublication history and additional material for this paper are available online. To view these files, please visit the journal online (http://dx.doi. org/10.1136/bmjopen-2017020270)

Received 26 0ctober 2017 Revised 31 January 2018 Accepted 5 February 2018

Check for updates

School of Pharmacy, Keele University, Keele, UK

Correspondence to

Natasha Slater;

n.slater@keele.ac.uk

\section{ABSTRACT}

Objectives While older age and ill health are known to be associated with polypharmacy, this paper aims to identify whether wealth, body mass index (BMI), smoking and alcohol consumption are also associated with polypharmacy (5-9 prescribed medications) and hyperpolypharmacy prevalence ( $\geq 10$ prescribed medications), among older people living in England. Design Cross-sectional study.

Setting The English Longitudinal Study of Ageing Wave 6 (2012-2013).

Participants 7730 participants aged over 50 years. Data synthesis Two multivariate models were created. HR with corresponding $95 \% \mathrm{Cl}$, for polypharmacy and hyperpolypharmacy, were calculated after adjusting for gender, age, wealth, smoking, alcohol consumption, BMI, self-rated health and the presence of a chronic health condition.

Results Lower wealth (lowest wealth quintile vs highest wealth quintile, adjusted $\mathrm{HR} 1.28 ; 95 \% \mathrm{Cl} 1.04$ to $1.69, \mathrm{P}=0.02$ ) and obesity (adjusted HR $1.81 ; 95 \% \mathrm{Cl}$ 1.53 to $2.15, p<0.01$ ) were significantly associated with polypharmacy. Increasing age (50-59years vs $70-79$ years, adjusted HR $3.42 ; 95 \% \mathrm{Cl} 2.81$ to 4.77 , $\mathrm{p}<0.01)$ and the presence of a chronic health condition (adjusted HR 2.94; 95\% Cl 2.55 to 3.39, $\mathrm{p}<0.01$ ) were also associated with polypharmacy. No statistically significant association between smoking and polypharmacy (adjusted HR 1.06; $95 \% \mathrm{Cl} 0.86$ to $1.29, \mathrm{P}=0.56$ ) was established; while, very frequent alcohol consumption (consuming alcohol $>5$ times per week) was inversely associated with polypharmacy (never drank alcohol vs very frequently, adjusted HR $0.64 ; 95 \% \mathrm{Cl} 0.52$ to $0.78, \mathrm{p}<0.01$ ). The adjusted HR for hyperpolypharmacy was accentuated, compared with polypharmacy.

Conclusion This study has identified that lower wealth, obesity, increasing age and chronic health conditions are significantly associated with polypharmacy and hyperpolypharmacy prevalence. The effect of these factors, on polypharmacy and especially hyperpolypharmacy prevalence, is likely to become more pronounced with the widening gap in UK wealth inequalities, the current obesity epidemic and the growing population of older people. The alcohol findings contribute to the debate on the relationship between alcohol consumption and health.
Strengths and limitations of this study

- This cross-sectional study uses medication data, from over 7000 older individuals, to identify factors which are associated with polypharmacy prevalence in primary care.

- In the analysis, a large number of covariates were used to minimise the impact of confounding factors.

- Participants were asked to self-report the information about their prescribed medication usage. To verify their responses, participants were asked to show their medication containers to the interviewer.

- Smoking and alcohol consumption data were also collected by asking participants to self-report. This relies on accurate and truthful information recall to prevent bias.

\section{INTRODUCTION}

Polypharmacy has been discussed extensively in the literature and media; however, there is no universally accepted definition for the practice of prescribing multiple medications to one individual. ${ }^{1}$ At present, polypharmacy is commonly defined as 'the use of five or more regular medications', while hyperpolypharmacy, which is sometimes termed as 'excessive polypharmacy', is defined as 'the use of ten or more regular medications'. Although polypharmacy prevalence has increased over the past decade, there are relatively few data about the factors associated with polypharmacy and hyperpolypharmacy in primary care. ${ }^{3}$

Previous studies have shown that increasing age and the presence of chronic conditions are significantly associated with an increase in polypharmacy prevalence. ${ }^{4-6}$ Comparatively fewer studies have examined whether sociodemographic or lifestyle factors, for example, wealth and obesity, are associated with polypharmacy. In a study conducted by Haider et $a l^{7}$ no statistically significant association between polypharmacy and an individual's 
socioeconomic status was established. The findings from a study by Rajska-Neumann $e t a l^{8}$ revealed that there was no statistically significant difference in polypharmacy prevalence between smokers and non-smokers; whereas a statistically significant inverse relationship between alcohol consumption and the concomitant administration of medications was detected by Wong et al. ${ }^{9}$ Finally, when Bueno et $a l^{10}$ examined the association between polypharmacy and obesity, an adjusted OR revealed that obese individuals (body mass index (BMI) $\geq 30 \mathrm{~kg} / \mathrm{m}^{2}$ ) were 1.6 times more likely to be experiencing polypharmacy, compared with individuals with a BMI $<30 \mathrm{~kg} / \mathrm{m}^{2}$. To evaluate the relationship between the aforementioned factors and polypharmacy prevalence in primary care, a large sample study is required.

This study used data from The English Longitudinal Study of Ageing (ELSA) as this provided an opportunity to link polypharmacy and hyperpolypharmacy data to participants' personal data. In particular, this study aimed to determine whether wealth, BMI, smoking, alcohol consumption, age and the presence of chronic health conditions are associated with polypharmacy (5-9 prescribed medications) and hyperpolypharmacy ( $\geq 10$ prescribed medications) prevalence in a community population of older people living in England.

\section{METHOD}

\section{Sample and participants}

A cross-sectional study was conducted using Wave 6 data from ELSA. Data collection took place between May 2012 and June 2013, from a representative sample of the English population who were aged 50 years or above.

Since ELSA began in 2002, participants have been asked to provide personal information about their household finances, health status, lifestyle choices and social interactions, on a biannual basis. In Wave 6, information from 10601 participants was collected, which included 9169 'core' participants. Members were considered 'core' if they were aged over 50 years old at the time of study enrolment and living at private residential addresses in England. ${ }^{11}$ Eight thousand and fifty-four nurse visits were completed at Wave 6 , of which 7730 were carried out with core members. This latter group is the focus of the current study. ${ }^{11}$

\section{Patient involvement and ethics}

All participants were required to provide informed written consent. ${ }^{12}$ All ELSA data are anonymous and freely accessible from the UK Data Service Discover. ${ }^{13}$ Only data contained within the ELSA database were included in the analyses. No patients were involved in the development of the research question, study design or interpretation of the data in this study.

\section{Data collection}

Face-to-face interviews

The face-to-face interviews were conducted by trained interviewers, who asked participants to provide information about their current lifestyle choices, including smoking habits and alcohol consumption over the past 12 months. Smoking status was recorded as current smoker or non-smoker; whereas, the frequency of alcohol consumption over the past year was recorded as never, rarely, frequently or very frequently. ${ }^{14}$ Rarely was defined as drinking alcohol less than two times in a month. Frequently was defined as drinking alcohol between one and four times a week; while, very frequently was defined as drinking alcohol at least five times a week.

Participants were also asked to describe their current health status. Participants could select one of the following options: 'excellent, very good, good, fair or poor' ${ }^{15}$ These responses were converted into a two-level variable: good/ fair and poor, with good/fair health status being the sum of responses ranging from 'excellent' to 'fair'. In a subsequent question, participants were asked whether they had any chronic health conditions. Participants could answer this question with either yes or no. ${ }^{15}$

Finally, participants were asked to provide information about their household income, including information about their employment status, personal finances, assets, pensions and other benefits. Participant pension data were excluded when wealth index scores were calculated. Based on their wealth index scores, participants were allocated to one of five wealth quintiles. Quintile 1 was the most affluent, while quintile 5 was the poorest.

\section{Questionnaire}

After completion of the face-to-face interview, participants were asked to complete a paper-based questionnaire. The questionnaire was designed to obtain further information about the participants' living arrangements, health status, lifestyle choices and social interactions. ${ }^{16}$

\section{Nurse visit}

The nurse visits took place in the participant's home. At the beginning of the visit, the nurse recorded information about participant demographics and their current prescribed medications. Prescribed medication formulations were defined by the nurses as 'pills, syrups, ointments, inhalers or injections'. ${ }^{17}$ If a participant reported taking one or more prescribed medications, the nurse sought their permission to record the name of their medication, in addition to seeing its container. The nurse determined current medication usage by asking the participant to confirm whether they had taken or used each reported medicine within the last 7 days. ${ }^{17}$ A maximum of 27 prescribed medications could be recorded for each participant. Medication information was coded by the nurse, according to the British National Formulary (BNF) (edition 61) chapter and subsection.

During the latter part of the visit, the nurse conducted a physical examination and recorded information about the participant's blood pressure, grip strength, height, weight and lung function. ${ }^{17}$ Using a participant's height and weight data, it was possible to calculate their BMI. A BMI $<18.5 \mathrm{~kg} / \mathrm{m}^{2}$ was recorded as underweight, a BMI 
value between $18.5 \mathrm{~kg} / \mathrm{m}^{2}$ and $24.9 \mathrm{~kg} / \mathrm{m}^{2}$ was considered to be normal weight; whereas, a BMI of $25.0-29.9 \mathrm{~kg} / \mathrm{m}^{2}$ was recorded as overweight and a BMI $\geq 30 \mathrm{~kg} / \mathrm{m}^{2}$ was recorded as obese.

\section{Inclusion criteria}

All participants must have completed a face-to-face interview, a paper-based questionnaire and received a nurse visit during ELSA Wave 6 to meet the inclusion criteria for this study. ${ }^{18}$

\section{Defining polypharmacy and hyperpolypharmacy}

Polypharmacy was defined as the concurrent use of 5-9 currently prescribed medications, while hyperpolypharmacy was defined as the concurrent use of $\geq 10$ currently prescribed medications. These definitions have been used previously in other population-based studies. ${ }^{3}{ }^{39}$

\section{Data analysis}

Initially, descriptive statistics were used to summarise the prevalence of polypharmacy and hyperpolypharmacy among participants. These data were subsequently stratified according to participant demographics. In the second part of the analysis, a bivariate model was used to assess the relationship between polypharmacy and the following independent variables: frequent alcohol consumption, increasing age, lower wealth, female sex, smoking, raised BMI, poor self-rated health and the presence of a chronic health condition. Bivariate correlations between other covariates were also examined. Findings were presented as Pearson's correlation coefficients $(r)$. The strength of each correlation was considered and described as either strong (1.00-0.50), moderate $(0.49$ $0.30)$ or weak $(0.29-0.10) .{ }^{20}$

In the final part of the analysis, two multivariate models were created to identify associations between participant characteristics and polypharmacy prevalence. Based on previous work by Peduzzi $e t a l,{ }^{21}$ the minimum sample size required for the first multivariate model (polypharmacy) was 333; while the minimum sample size required for the second multivariate model (hyperpolypharmacy) was 1250. In both models, ill health was controlled for by using participants taking between one and four prescribed medications. This group of participants formed the control group. Participants taking no prescribed medications were excluded from this part of the analysis. In the first model, participants taking 5-9 medications were compared with the control group (1-4 prescribed medications). In the second model, participants taking $\geq 10$ medications were compared with the control group (1-4 prescribed medications). HRs with corresponding $95 \% \mathrm{CI}$, for polypharmacy and hyperpolypharmacy, were calculated after adjusting for covariates. The following factors were considered as covariates: gender, age, wealth, smoking, alcohol consumption, BMI, self-rated health and the presence of a chronic health condition. Missing data were coded as 'missing' and presented as a separate category in the multivariate models. The data generated from the models were considered to be statistically significant if $\mathrm{P}<0.05$. All data analyses were undertaken using SPSS V.24.0.

\section{RESULTS}

\section{Participant characteristics}

A total of 7730 participants' data from ELSA Wave 6 were analysed. Participant characteristics are presented in table 1. The mean age of participants in Wave 6 was 67.6years, and $55.4 \%(\mathrm{n}=4282 / 7730)$ of the sample were women. Overall, $24.1 \%(\mathrm{n}=1862 / 7725)$ of the participants received polypharmacy and $6.4 \%(\mathrm{n}=494 / 7725)$ were receiving hyperpolypharmacy (table 1). The proportion of individuals receiving polypharmacy and hyperpolypharmacy increased steadily with age. However, the prevalence of polypharmacy and hyperpolypharmacy in men and women was similar (table 1).

\begin{tabular}{|c|c|c|c|c|}
\hline & No medications & 1-4 medications & 5-9 medications & $\geq 10$ medications \\
\hline Participant characteristics & & & Polypharmacy & Hyperpolypharmacy \\
\hline \multicolumn{5}{|c|}{ Missing medication data $(n=5)$} \\
\hline \multicolumn{5}{|l|}{ Age (years) } \\
\hline $60-69(n=3012)$ & $26.6 \%$ & $49.2 \%$ & $19.6 \%$ & $4.6 \%$ \\
\hline $70-79(n=2114)$ & $11.8 \%$ & $45.9 \%$ & $33.1 \%$ & $9.2 \%$ \\
\hline $80+(n=909)$ & $6.4 \%$ & $39.6 \%$ & $41.3 \%$ & $12.7 \%$ \\
\hline \multicolumn{5}{|l|}{ Gender } \\
\hline Male $(n=3448)$ & $24.9 \%$ & $44.6 \%$ & $24.4 \%$ & $6.1 \%$ \\
\hline No $(n=3441)$ & $41.6 \%$ & $47.1 \%$ & $10.3 \%$ & $1.0 \%$ \\
\hline
\end{tabular}



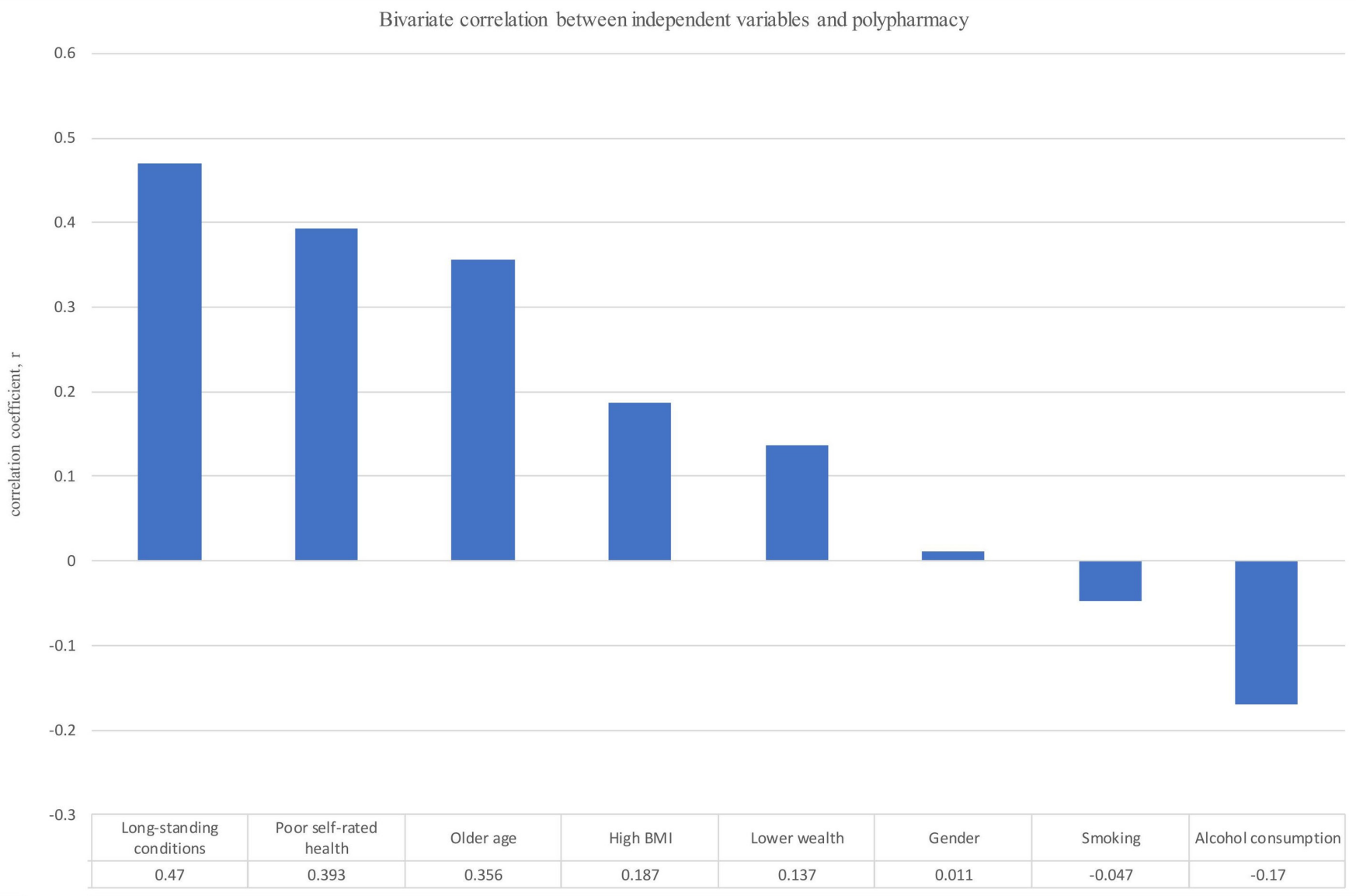

Figure 1 Bivariate correlations between polypharmacy and covariates. BMI, body mass index.

Overall, $35.2 \% \quad(n=1509 / 4289)$ of participants who reported having a chronic health condition were receiving polypharmacy; whereas, $10.7 \% \quad(\mathrm{n}=459 / 4289)$ were receiving hyperpolypharmacy. Only $10.3 \%(n=353 / 3441)$ and $1.0 \%(\mathrm{n}=35 / 3441)$ of participants with no chronic health conditions, received polypharmacy and hyperpolypharmacy, respectively (table 1 ).

In a bivariate model, moderate positive correlations were detected between polypharmacy and the following variables: the presence of a chronic health condition, poor self-rated health and increasing age. A weak positive correlation between polypharmacy and a high BMI was established. Similarly, there was a weak positive correlation between lower wealth and polypharmacy. No correlations between gender and polypharmacy, and smoking and polypharmacy, were established. However, there was a weak negative correlation between polypharmacy and frequent alcohol consumption. All bivariate correlations are presented in figure 1. Bivariate correlations between other covariates were also examined, and data are available in online supplementary table 1 .

To determine whether other variables are associated with polypharmacy and hyperpolypharmacy, the results from the two multivariate models (polypharmacy-1 and hyperpolypharmacy-2) were analysed and presented in tables 2 and 3 , respectively.

\section{Examining the association between age and polypharmacy}

In both models, increasing age was associated with polypharmacy and hyperpolypharmacy. For participants aged between 70 years and 79 years, the adjusted HR for polypharmacy was 3.42 (2.81 to $4.77, \mathrm{p}<0.01)$ (table 2). This value increased to 4.52 (3.58 to $5.70, \mathrm{p}<0.01$ ) in participants aged $\geq 80$ years old (table 2). Similarly, the adjusted HRs for hyperpolypharmacy increased from 4.11 (2.77 to 6.09, $\mathrm{p}<0.01)$ in participants aged between 70 years and 79 years to 5.94 (3.79 to $9.29, \mathrm{p}<0.01)$ in participants aged $\geq 80$ years old (table 3 ). All findings were statistically significant.

Examining the association between the presence of a chronic health condition and polypharmacy

The adjusted HR for polypharmacy and the presence of a chronic health condition was 2.94 (2.55 to 3.39, $\mathrm{p}<0.01$ ) (table 2), whereas for hyperpolypharmacy and the presence of a chronic health condition, it was 5.30 (3.63 to $7.73, \mathrm{p}<0.01$ ) (table 3 ). In both models, statistically significant results were generated.

Examining the association between wealth and polypharmacy The adjusted HR for polypharmacy increased from 1.08 ( 0.9 to $1.31, \mathrm{P}=0.37$ ) in wealth quintile 2 to 1.28 (1.04 to $1.69, \mathrm{P}=0.02$ ) in wealth quintile 5 (table 2). Similarly, the adjusted HR for hyperpolypharmacy increased from 1.41 (0.93 to $2.13, \mathrm{P}=0.11$ ) in wealth quintile 2 to 2.04 (1.34 
Table 2 Model 1: independent variables for polypharmacy (5-9 medications, $n=2356)$ versus no polypharmacy (1-4 medications, $\mathrm{n}=3532$ )

\begin{tabular}{|c|c|c|c|c|}
\hline \multirow[b]{2}{*}{ Independent variables } & \multirow[b]{2}{*}{ Adjusted HR } & \multicolumn{2}{|l|}{$95 \% \mathrm{Cl}$} & \multirow[b]{2}{*}{ Significance } \\
\hline & & Lower & Upper & \\
\hline \multicolumn{5}{|l|}{ Age (years) } \\
\hline $60-69(n=2210)$ & 1.66 & 1.37 & 2.01 & $<0.01$ \\
\hline $70-79(n=2344)$ & 3.42 & 2.81 & 4.77 & $<0.01$ \\
\hline Male (reference) $(n=2588)$ & 1 & & & \\
\hline Female $(\mathrm{n}=3300)$ & 0.92 & 0.81 & 1.04 & 0.21 \\
\hline \multicolumn{5}{|l|}{ Chronic health condition } \\
\hline No (reference) $(n=2008)$ & 1 & & & \\
\hline Self-rated health: good (reference) $(n=3907)$ & 1 & & & \\
\hline Self-rated health: poor $(n=1978)$ & 2.98 & 2.61 & 3.4 & $<0.01$ \\
\hline \multicolumn{5}{|l|}{ Missing self-rated health data $(n=3)$} \\
\hline \multicolumn{5}{|l|}{ Wealth } \\
\hline Wealth: quintile 1 (wealthiest) (reference) $(n=1237)$ & 1 & & & \\
\hline Wealth: quintile $2(n=1244)$ & 1.08 & 0.9 & 1.31 & 0.37 \\
\hline Wealth: quintile 3 ( $n=1196)$ & 1.13 & 0.93 & 1.37 & 0.19 \\
\hline Wealth: quintile $4(n=1190)$ & 1.23 & 1.02 & 1.5 & 0.03 \\
\hline Wealth: quintile 5 (poorest) ( $n=921)$ & 1.28 & 1.04 & 1.69 & 0.02 \\
\hline$\geq 30:$ obese $(n=1930)$ & 1.81 & 1.53 & 2.15 & $<0.01$ \\
\hline \multicolumn{5}{|l|}{ Missing BMI data $(n=319)$} \\
\hline \multicolumn{5}{|l|}{ Current smoking habits since last ELSA interview } \\
\hline Non-smoker (reference) $(n=3153)$ & 1 & & & \\
\hline Smoker $(\mathrm{n}=650)$ & 1.06 & 0.86 & 1.29 & 0.56 \\
\hline \multicolumn{5}{|l|}{ Missing smoking data $(n=2085)$} \\
\hline \multicolumn{5}{|l|}{ Alcohol consumption in past 12 months } \\
\hline Never (reference) $(n=792)$ & 1 & & & \\
\hline Rarely $(n=930)$ & 0.76 & 0.61 & 0.94 & 0.01 \\
\hline Frequently $(n=1797)$ & 0.65 & 0.53 & 0.79 & $<0.01$ \\
\hline Very frequently $(n=1791)$ & 0.64 & 0.52 & 0.78 & $<0.01$ \\
\hline Missing alcohol consumption data $(n=578)$ & & & & \\
\hline
\end{tabular}

BMI, body mass index; ELSA, The English Longitudinal Study of Ageing.

to $3.11, \mathrm{p}<0.01$ ) in wealth quintile 5 (table 3 ). In both models, statistically significant differences in adjusted HRs for polypharmacy and hyperpolypharmacy were detected in the lower wealth quintiles (quintile 4 and 5).
Examining the association between BMI and polypharmacy In underweight participants, the adjusted HR for polypharmacy was 0.93 ( 0.5 to $1.74, \mathrm{P}=0.83$ ) (table 2 ); whereas, the adjusted HRs for polypharmacy in participants who 
Table 3 Model 2: independent variables for hyperpolypharmacy ( 210 medications, $n=494)$ versus no polypharmacy $(1-4$ medications, $\mathrm{n}=3532$ )

\begin{tabular}{|c|c|c|c|c|}
\hline \multirow[b]{2}{*}{ Independent variables } & \multirow[b]{2}{*}{ Adjusted HR } & \multicolumn{2}{|l|}{$95 \% \mathrm{Cl}$} & \multirow[b]{2}{*}{ Significance } \\
\hline & & Lower & Upper & \\
\hline \multicolumn{5}{|l|}{ Age (years) } \\
\hline $50-59$ (reference) $(n=765)$ & 1 & & & \\
\hline $60-69(n=1620)$ & 1.79 & 1.21 & 2.64 & $<0.01$ \\
\hline $70-79(n=1444)$ & 4.11 & 2.77 & 6.09 & $<0.01$ \\
\hline $80+(n=197)$ & 5.94 & 3.79 & 9.29 & $<0.01$ \\
\hline \multicolumn{5}{|l|}{ Gender } \\
\hline Male (reference) $(n=1748)$ & 1 & & & \\
\hline Female (n=2278) & 0.94 & 0.71 & 1.15 & 0.41 \\
\hline \multicolumn{5}{|l|}{ Chronic health condition } \\
\hline No (reference) (n=1656) & 1 & & & \\
\hline Yes $(n=2370)$ & 5.30 & 3.63 & 7.73 & $<0.01$ \\
\hline \multicolumn{5}{|l|}{ Self-rated health } \\
\hline Self-rated health: good (reference) $(n=2944)$ & 1 & & & \\
\hline Self-rated health: poor $(n=1081)$ & 6.69 & 5.21 & 8.58 & $<0.01$ \\
\hline \multicolumn{5}{|l|}{ Missing self-rated health data $(n=1)$} \\
\hline \multicolumn{5}{|l|}{ Wealth } \\
\hline Wealth: quintile 1 (wealthiest) (reference) $(n=907)$ & 1 & & & \\
\hline Wealth: quintile 2 ( $n=875)$ & 1.41 & 0.93 & 2.13 & 0.11 \\
\hline Wealth: quintile 3 ( $n=797)$ & 1.36 & 0.90 & 2.06 & 0.15 \\
\hline Wealth: quintile $4(n=756)$ & 1.75 & 1.17 & 2.60 & $<0.01$ \\
\hline Wealth: quintile 5 (poorest) $(n=611)$ & 2.04 & 1.34 & 3.11 & $<0.01$ \\
\hline \multicolumn{5}{|l|}{ Missing wealth data $(n=80)$} \\
\hline \multicolumn{5}{|l|}{$\mathrm{BMI}\left(\mathrm{kg} / \mathrm{m}^{2}\right)$} \\
\hline$<18.5$ : underweight $(\mathrm{n}=38)$ & 0.88 & 0.26 & 2.95 & 0.83 \\
\hline 18.5-24.9: normal (reference) $(n=959)$ & 1 & & & \\
\hline 25.0-29.9: overweight $(n=1633)$ & 1.38 & 0.98 & 1.95 & 0.07 \\
\hline$\geq 30:$ obese $(n=1205)$ & 2.28 & 1.63 & 3.21 & $<0.01$ \\
\hline \multicolumn{5}{|l|}{ Missing BMI data $(\mathrm{n}=191)$} \\
\hline \multicolumn{5}{|l|}{ Current smoking habits since last ELSA interview } \\
\hline Non-smoker (reference) $(n=2077)$ & 1 & & & \\
\hline Smoker $(n=424)$ & 0.98 & 0.68 & 1.39 & 0.89 \\
\hline \multicolumn{5}{|l|}{ Missing smoking data $(n=1525)$} \\
\hline \multicolumn{5}{|l|}{ Alcohol consumption in past 12 months } \\
\hline Never (reference) $(n=489)$ & 1 & & & \\
\hline Rarely $(n=619)$ & 0.70 & 0.50 & 0.99 & 0.05 \\
\hline Frequently $(n=1256)$ & 0.40 & 0.29 & 0.56 & $<0.01$ \\
\hline Very frequently $(n=1293)$ & 0.39 & 0.27 & 0.55 & $<0.01$ \\
\hline Missing alcohol consumption data $(n=369)$ & & & & \\
\hline
\end{tabular}

BMI, body mass index; ELSA, The English Longitudinal Study of Ageing.

were overweight or obese were 1.13 (0.96 to $1.33, \mathrm{P}=0.13$ ) and 1.81 (1.53 to 2.15, $\mathrm{p}<0.01$ ), respectively (table 2 ). Adjusted HRs for hyperpolypharmacy produced similar results. In underweight participants, the adjusted HR for hyperpolypharmacy decreased to 0.88 (0.26 to 2.95, $\mathrm{P}=0.83$ ) (table 3); whereas, the adjusted HR for hyperpolypharmacy in overweight participants was 1.38 (0.98 to $1.95, \mathrm{P}=0.07)$ increasing substantially to 2.28 (1.63 to 3.21, $\mathrm{p}<0.01$ ) in obese participants (table 3). Only the adjusted HRs for polypharmacy and hyperpolypharmacy, in relation to obesity, produced statistically significant results. 


\section{Examining the association between smoking and} polypharmacy

The adjusted HR for polypharmacy and smoking was 1.06 (0.86 to $1.29, \mathrm{P}=0.56$ ) (table 2 ), whereas the adjusted HR for hyperpolypharmacy and smoking was 0.98 (0.68 to 1.39, $\mathrm{P}=0.89$ ) (table 3). Both models failed to produce any statistically significant results.

\section{Examining the association between alcohol consumption and polypharmacy}

Adjusted HRs for polypharmacy and hyperpolypharmacy were calculated using the participant's alcohol consumption data provided during the face-to-face interview. When compared with individuals who reported never drinking alcohol, the adjusted HR for participants who reported rarely consuming alcohol was 0.76 (0.61 to $0.94, \mathrm{P}=0.01$ ) (table 2). This value decreased further to $0.64(0.52$ to $0.78, \mathrm{p}<0.01)$ in participants who reported drinking alcohol very frequently (table 2 ). The adjusted HRs for hyperpolypharmacy produced similar results. For participants who reported rarely consuming alcohol, the adjusted HR for hyperpolypharmacy was $0.70(0.50$ to $0.99, \mathrm{P}=0.05$ ), when compared with individuals who reported never drinking alcohol (table 3); whereas the adjusted HR for hyperpolypharmacy in participants who reported drinking alcohol frequently was 0.39 ( 0.27 to $0.55, \mathrm{p}<0.01$ ) (table 3 ). All adjusted HRs for polypharmacy and hyperpolypharmacy, in relation to self-reported alcohol consumption, were statistically significant.

\section{DISCUSSION}

This study confirms that increasing age and the presence of chronic health conditions are associated with polypharmacy prevalence, but also that obesity and lower wealth are significantly associated with polypharmacy. Frequent alcohol consumption is inversely associated with polypharmacy prevalence. Results from previous studies, which have investigated the influence of ageing and chronic health conditions on polypharmacy prevalence, complement our findings. ${ }^{192} 23$

In the existing literature, few studies have investigated whether polypharmacy prevalence is associated with wealth or BMI. ${ }^{24}{ }^{25}$ One study conducted in Rome, analysed a national prescription database and a multivariate model was used to identify participant characteristics which influenced polypharmacy prevalence. ${ }^{24}$ The authors concluded that individuals living in lower socioeconomic areas are $33 \%$ more likely to experience polypharmacy compared with individuals living in higher socioeconomic areas. In our study, participants were allocated to one of five wealth quintiles, based on their wealth index scores. Participants living in the lowest wealth quintiles were $28 \%$ more likely to experience polypharmacy and twice as likely to experience hyperpolypharmacy, when compared with participants living in the highest wealth quintile. Our findings show that lower wealth is significantly associated with an increase in polypharmacy and hyperpolypharmacy prevalence. This finding is important because the latest figures published by the Office of National Statistics ${ }^{25}$ show that wealth inequalities across the UK have begun to rise again, after a decade-long decline. There is also evidence to suggest that the incidence of chronic health conditions and multimorbidities is highest among individuals residing in deprived areas. ${ }^{26}{ }^{27}$ The aforementioned individuals are likely to require multiple medications to manage or treat their chronic conditions and thus, providing support for the association between lower wealth and polypharmacy.

Our multivariate model also revealed that obesity (BMI $\geq 30 \mathrm{~kg} / \mathrm{m}^{2}$ ) was another factor associated with polypharmacy and hyperpolypharmacy prevalence. This finding was statistically significant. The same association was identified during another study; however, the authors did not comment on the statistical significance of their results, nor did they conduct any further research into the association. ${ }^{28}$ Identifying the association between polypharmacy and obesity is also important because obesity has become a major public health concern in England. Assuming the current obesity epidemic continues as predicted, the prevalence of polypharmacy and hyperpolypharmacy among older people in England, is likely to follow suit. ${ }^{29}$

This study found no statistically significant association between smoking and polypharmacy. Similarly, there were no statistically significant association between smoking and hyperpolypharmacy. Our findings are supported by Rajska-Neumann et $a l^{8}$ and Henderson et al. ${ }^{30}$ However, another study reports that smoking is inversely associated with polypharmacy (adjusted OR 0.42; 95\% CI 0.33 to $0.53) .^{31}$

Frequent alcohol consumption in the past year was inversely associated with polypharmacy and hyperpolypharmacy prevalence. This finding is consistent with previous work, involving ELSA, which reported that self-reported alcohol consumption (even at high levels) was not related to poor self-rated health. ${ }^{32} 33$ The alcohol findings in this current study could be explained by the sick quitter hypothesis, where individuals stop or reduce their alcohol consumption due to illness. ${ }^{34}$ However, Rimm and Moats ${ }^{35}$ conclude that the sick quitter hypothesis has been refuted by a wide range of evidence. The inverse association between alcohol consumption and polypharmacy was also detected by Incalzi $e t$ al, ${ }^{31}$ although they appear to discount a genuine association and rather attribute this to bias (ie, patients in better health are less motivated to correct unhealthy habits).

Finally, most of the existing literature suggest that women take more medications compared with men; however, our study found that there was no statistically significant difference in polypharmacy and hyperpolypharmacy prevalence between men and women. ${ }^{36-38}$ Pan et $a \vec{l}^{39}$ provide support for our findings and concluded that the female sex is not significantly associated with an increased polypharmacy prevalence. 
To our knowledge this is the first study which has used medication data, from a large representative sample of older adults, to determine whether lower wealth, obesity, smoking, alcohol consumption, in addition to increasing age and the presence of chronic health conditions, are associated with polypharmacy and hyperpolypharmacy prevalence in primary care. All analysed data were obtained using standardised data collection methods and validated data collection tools. Also, this study used a large number of covariates, which reduced the impact of confounders and minimised study bias.

This study has several limitations. Actual medication use among participants may have been higher than recorded medication use for several reasons. First, participants were asked about their prescribed medications; however, medications purchased without prescription, for example, weak analgesics or antihistamines, were not recorded. Second, prescribed medications were coded according to BNF chapter and subsection. It was assumed that each code represented a single active ingredient; however, several combination drugs, for example, co-amilofruse and co-amilozide, were also represented by a single code. Furthermore, when the nurse enquired about prescribed medications, they asked the following question: 'Are you taking or using any medications, pills, syrups, ointments, puffers or injections prescribed to you by a doctor or a nurse? ${ }^{19}$ This question refers to some medicinal formulations, but the list is not exhaustive. Thus, a participant using eye drops or wearing a transdermal patch may not have reported this medication as the formulation was not explicitly stated in the question. Consequently, polypharmacy and hyperpolypharmacy prevalence may have been underestimated in this study.

To obtain data about prescribed medications, smoking habits and alcohol consumption, participants were asked to self-report. This method of data collection relies on all participants accurately and truthfully recalling information to prevent bias. ${ }^{40}$ The risk of recall bias associated with prescribed medication information was minimised by the nurse because participants were asked to show their medication containers to verify their responses. However, it was not possible to minimise the risk of recall bias associated with the other covariates. Participants also reported information about chronic health conditions; however, the associations between specific health conditions, multimorbidity and polypharmacy were not examined in this study. Finally, it is not possible to determine the direction of causality from our data, due to the cross-sectional nature of this study.

\section{CONCLUSION}

This study has identified that lower wealth, obesity, increasing age and the presence of chronic health conditions are all associated with polypharmacy and hyperpolypharmacy prevalence, among older people in primary care. An inverse relationship between frequent alcohol consumption and polypharmacy prevalence was also established. In the future, the effect of obesity and lower wealth on polypharmacy and hyperpolypharmacy prevalence is likely to become more pronounced, as the gap in UK wealth inequalities begins to widen again and the UK obesity epidemic continues. Future exploratory work is required to determine the causation behind these associations.

Acknowledgements The authors would like to thank the ELSA participants, the ELSA researchers and the UK Data Service for enabling the use of ELSA data for this analysis.

Contributors All authors contributed to the study idea. MF led the study and conducted all data analysis. All authors had full access to ELSA Wave 6 data, supplied by the UK Data Service and they take full responsibility for the integrity and accurate analysis of data. All authors contributed to data interpretation. NS drafted the manuscript with contributions from MF, RV and SW. NS and MF are the guarantors for this study.

Funding This research received no specific grant from any funding agency in the public, commercial or not-for-profit sectors.

Competing interests None declared.

Patient consent Not obtained.

Ethics approval Ethical approval for ELSA Wave 6 was granted by the National Research Ethics Committee under the National Research and Ethics Service.

Provenance and peer review Not commissioned; externally peer reviewed.

Data sharing statement № additional data is available; however, anonymous ELSA data are publicly available from http://discover.ukdataservice.ac.uk/

Open Access This is an Open Access article distributed in accordance with the Creative Commons Attribution Non Commercial (CC BY-NC 4.0) license, which permits others to distribute, remix, adapt, build upon this work non-commercially, and license their derivative works on different terms, provided the original work is properly cited and the use is non-commercial. See: http://creativecommons.org/ licenses/by-nc/4.0/

(C) Article author(s) (or their employer(s) unless otherwise stated in the text of the article) 2018. All rights reserved. No commercial use is permitted unless otherwise expressly granted.

\section{REFERENCES}

1. Duerden M, Payne R. Polypharmacy - what is it and how common is it? Prescriber 2014;25:44-7.

2. O'Dwyer M, Peklar J, McCallion P, et al. Factors associated with polypharmacy and excessive polypharmacy in older people with intellectual disability differ from the general population: a cross-sectional observational nationwide study. BMJ Open 2016;6:e010505.

3. Guthrie B, Makubate B, Hernandez-Santiago V, et al. The rising tide of polypharmacy and drug-drug interactions: population database analysis 1995-2010. BMC Med 2015;13:74.

4. The Dynamics of Ageing. Evidence from the English Longitudinal Study of Ageing (Wave 7).2002-15 www.ifs.org.uk/uploads/elsa/ docs_w7/report.pdf (accessed 27 Jul 2017).

5. Department of Health. Long Term Condition Compendium of Information. Third Edition, 2012. www.gov.uk/government/uploads/ attachment_data/file/216528/dh_134486.pdf (accessed 27 Jul 2017).

6. Silveira EA, Dalastra L, Pagotto V. Polypharmacy, chronic diseases and nutritional markers in community-dwelling older. Rev Bras Epidemiol 2014;17:818-29.

7. Haider SI, Johnell K, Thorslund M, et al. Analysis of the association between polypharmacy and socioeconomic position among elderly aged $>$ or $=77$ years in Sweden. Clin Ther 2008;30:419-27.

8. Rajska-Neumann A, Szymański M, Balcer N, et al. [ls smoking a determinant of polypharmacy among elderly subject?]. Przegl Lek 2005;62:1145-7.

9. Wong $\mathrm{H}$, Heuberger R, Logomarsino J, et al. Associations between alcohol use, polypharmacy and falls in older adults: Helen Wong and colleagues report on a cross-sectional study into alcohol consumption, medication use and falls in the community. Nursing older people 2016;28:30-6. 
10. Bueno DR, Monteiro HL, Rosa CS, et al. Association between physical activity levels and polypharmacy in hypertensive patients. Medicina 2016;49:240-7.

11. Wade KF, Marshall A, Vanhoutte B, et al. Does pain predict frailty in older men and women? Findings from the English Longitudinal Study of Ageing (ELSA). J Gerontol A Biol Sci Med Sci 2017;72:403-9.

12. English Longitudinal Study of Ageing (ELSA) Wave 1 to Wave 6. http://doc.ukdataservice.ac.uk/doc/5050/mrdoc/pdf/5050_elsa_ user_guide_waves_1-6_v3.pdf (accessed 8 Dec 2017).

13. UK Data Service Discover. English longitudinal study of ageing. https://discover.ukdataservice.ac.uk/series/?sn=200011 (accessed 8 Dec 2017).

14. Lee DM, Nazroo J, O'Connor DB, et al. Sexual health and well-being among older men and women in England: Findings from the English Longitudinal Study of Ageing. Arch Sex Behav 2016:45:133-44.

15. Nat Cen Social Research. English Longitudinal Study of Ageing Wave 6 interview questionnaire. Version 3.0. https://www.elsa-project.ac. uk/uploads/elsa/docs w6/main questionnaire.pdf (accessed 5 Sep 2017).

16. English longitudinal study of ageing health and lifestyles of people aged 50 or over. Self-completion questionnaire. https://www.elsaproject.ac.uk/uploads/elsa/docs_w6/self_completion_main.pdf (accessed 5 Sep 2017).

17. Nat Cen Social Research. English longitudinal study of ageing wave 6 nurse questionnaire. 2012-2013 https://www.elsa-project.ac.uk/ uploads/elsa/docs w6/nurse documentation.pdf (accessed 5 Sep 2017)

18. Steptoe A, Breeze E, Banks J, et al. Cohort profile: the English longitudinal study of ageing. Int J Epidemiol 2013;42:1640-8.

19. Bjerrum L, Søgaard J, Hallas J, et al. Polypharmacy: correlations with sex, age and drug regimen a prescription database study. Eur J Clin Pharmacol 1998;54:197-202.

20. Statistical Correlation. The relationship between two variables. https://explorable.com/statistical-correlation (accessed 8 Dec 2017).

21. Peduzzi P, Concato J, Kemper E, et al. A simulation study of the number of events per variable in logistic regression analysis. $J$ Clin Epidemiol 1996;49:1373-9.

22. The Irish Longitudinal Study of Ageing. Main Questionnaire. 2010 http://www.ucd.ie/issda/static/documentation/tilda/tilda-capi-qairewave1.pdf (accessed 5Sep 2017)

23. Tjia J, Velten SJ, Parsons C, et al. Studies to reduce unnecessary medication use in frail older adults: a systematic review. Drugs Aging 2013;30:285-307.

24. Fano V, Chini F, Pezzotti P, Bontempi K. Estimating the prevalence and the determinants of polypharmacy using data from a Health Administrative Database: a comparison of results obtained employing different algorithms. Adv Pharmacoepidemiol Drug Saf 2014:3:2167-1052.

25. The Office of National Statistics Report: Chapter 2 Total Wealth, Wealth in GB, 2012-2014. http://webarchive.nationalarchives.gov. uk/20160105170657/http://www.ons.gov.uk/ons/rel/was/wealth-ingreat-britain-wave-4/2012-2014/rpt-chapter-2.html

26. Kings Fund. Long term conditions. https://www.kingsfund.org.uk/ projects/time-think-differently/trends-disease-and-disability-longterm-conditions-multi-morbidity

27. Barnett K, Mercer SW, Norbury M, et al. Epidemiology of multimorbidity and implications for health care, research, and medical education: a cross-sectional study. Lancet 2012;380:37-43.

28. Counterweight Project Team. The impact of obesity on drug prescribing in primary care. Br J Gen Pract 2005;55:743.

29. Wang YC, McPherson K, Marsh T, et al. Health and economic burden of the projected obesity trends in the USA and the UK. Lancet 2011:378:815-25.

30. Henderson JA, Buchwald D, Manson SM. Relationship of medication use to health-related quality of Life among a group of older American Indians. Journal of Applied Gerontology 2006;25(1_ suppl):89S-104.

31. Antonelli Incalzi R, Corsonello A, Pedone C, et al. Depression and drug utilization in an elderly population. Ther Clin Risk Manag 2005;1:55-60.

32. Frisher $\mathrm{M}$, Mendonça $\mathrm{M}$, Shelton $\mathrm{N}$, et al. Is alcohol consumption in older adults associated with poor self-rated health? Cross-sectional and longitudinal analyses from the English Longitudinal Study of Ageing. BMC Public Health 2015;15:703.

33. Holdsworth $\mathrm{C}$, Mendonça $\mathrm{M}$, Pikhart $\mathrm{H}$, et al. Is regular drinking in later life an indicator of good health? Evidence from the English Longitudinal Study of Ageing. J Epidemiol Community Health 2016;70:764-70.

34. Shaper AG, Wannamethee G, Walker M. Alcohol and mortality in British men: Explaining the U-shaped curve. The Lancet 1988;332:1267-73.

35. Rimm EB, Moats C. Alcohol and coronary heart disease: drinking patterns and mediators of effect. Ann Epidemiol 2007;17:S3-7.

36. Kaufman DW, Kelly JP, Rosenberg L, et al. Recent patterns of medication use in the ambulatory adult population of the United States. JAMA 2002;287:337-44.

37. Schuler J, Dückelmann C, Beindl W, et al. Polypharmacy and inappropriate prescribing in elderly internal-medicine patients in Austria. Wien Klin Wochenschr 2008;120:733-41.

38. Wauters $\mathrm{M}$, Elseviers $\mathrm{M}$, Vaes $\mathrm{B}$, et al. Polypharmacy in a Belgian cohort of community-dwelling oldest old (80+). Acta Clin Belg 2016:71:158-66.

39. Pan HH, Li CY, Chen TJ, et al. Association of polypharmacy with fall-related fractures in older Taiwanese people: age- and genderspecific analyses. BMJ Open 2014;4:e004428. Depression and drug utilization in an elderly population.

40. Barker C, Pistrang N, Elliott R. Self-report methods, in research methods in clinical psychology: an introduction for students and practitioners. Second Edition. Chichester, UK: John Wiley \& Sons, Ltd, 2002. 